\title{
Mathematical modeling of the diffusion of liquids in the gaseous phase by evaporation
}

\section{Modelado matemático de la difusión de líquidos en fase gaseosa por evaporación}

\author{
LOPEZ-VALDIVIESO, Leticia†*, ELISEO-DANTÉS, Hortensia, CASTRO-DE LA CRUZ, Jucelly and \\ TEJERO-RIVAS, María Candelaria
}

Tecnológico Nacional de México/Instituto Tecnológico de Villahermosa

ID $1^{\text {st }}$ Author: Leticia, López-Valdivieso / ORC ID: 0000-0001-6288-3636, Researcher ID Thomson: G-5753-2018, CVU CONACYT ID: 67839

ID $1^{\text {st }}$ Coauthor: Hortensia, Eliseo-Dantés / ORC ID: 0000-0003-4006-4669, Researcher ID Thomson: F-6749-2018, CVU CONACYT ID: 411079

ID $2^{\text {nd }}$ Coauthor: María Candelaria, Tejero-Rivas / ORC ID: 0000-0002-1753-0767, Researcher ID Thomson: ABC-20572020, CVU CONACYT ID: 668744

ID $3^{\text {rd }}$ Coauthor: Jucelly, Castro-De La Cruz / ORC ID: 0000-0002-3862-9555, Researcher ID Thomson: G-1886-2018, CVU CONACYT ID: 739319

DOI: $10.35429 / J T D .2020 .14 .4 .15-19$

Received June 26, 2020; Accepted November 28, 2020

\begin{abstract}
The objective of this study is to analyze the behavior of liquid molecules during an evaporation process, a mathematical model is proposed through mass a balance that describes said behavior under steady-state conditions and the variation in composition is analyzed in detail, through a finite space. In order to know the concentration profile, it is necessary to characterize the behavior of the moisture present in the medium as part of the parameters that affect the system, which will at the same time allow knowing the molar composition of the water present in the medium or system of study. Temperature is another of the variables of great importance in the evaporation process, which is why a variation of the concentration profile will occur at different temperatures.
\end{abstract}

Evaporation, Profile, Concentration

\section{Resumen}

El objetivo de este estudio es analizar el comportamiento de las moléculas del líquido durante un proceso de evaporación, se plantea a través de balances de materia un modelo matemático que describe dicho comportamiento bajo condiciones de estado estable y se analiza a detalle la variación de la composición a través de un espacio finito determinado. Con el fin de conocer el perfil de concentración es necesario caracterizar el comportamiento de la humedad presente en el medio como parte de los parámetros que afectan el sistema, lo que permitirá a la vez saber la composición molar del agua presente en el medio o sistema de estudio. La temperatura es otra de las variables de gran importancia en el proceso de evaporación por lo que se presentará una variación del perfil de concentración a diferentes temperaturas.

Evaporación, Perfil, Concentración.

Citation: LOPEZ-VALDIVIESO, Leticia, ELISEO-DANTÉS, Hortensia, CASTRO-DE LA CRUZ, Jucelly and TEJERORIVAS, María Candelaria. Mathematical modeling of the diffusion of liquids in the gaseous phase by evaporation. Journal of Technological Development. 2020. 4-14: 15-19

\footnotetext{
* Correspondence to Author (email: leticia.lv@ villahermosa.tecnm.mx)

$\uparrow$ Researcher contributing first author
} 


\section{Introduction}

Evaporation is an essential part of the water cycle, solar energy accelerates the evaporation process. For the molecules of a liquid to evaporate, they must be located near the surface, move in the proper direction, and have enough energy to overcome the intermolecular forces of the liquid phase. Not all molecules meet these criteria, this is the cause of the limited evaporation of these molecules. The kinetic energy of a molecule is proportional to its temperature, evaporation takes place more rapidly as the temperature is higher, because the faster-moving molecules escape, the remaining molecules have a lower average kinetic energy, and therefore the temperature of the liquid decreases. Three key factors affect evaporation: heat, humidity, and air movement.

A more detailed analysis of the factors that influence the evaporation rate allows us to recognize that: a) if the air has a high concentration of the evaporating substance, then the substance will evaporate more slowly, b) if the liquid contains other substances, it will have a lower capacity for evaporation, c) The temperature allows to accelerate the evaporation process, so if the temperature rises the evaporation will be faster, d) the greater the forces that hold the molecules together in the liquid, more energy will be needed to evaporate them, and e) a substance that has a larger surface area will evaporate faster, since there are more surface molecules that are able to escape.

In general, considering the evaporation of a free water surface (lake, river, lagoon, etc.) as the simplest form of the process, this is carried out as follows: The water molecules are in continuous movement, When they reach the surface of the liquid, they are heated by the effect of solar radiation, they increase their temperature and consequently their speed, thus increasing their kinetic energy, until some manage to free themselves from the attraction of adjacent molecules and cross the interface. liquid-gas, turning into vapor. However, the layer of air immediately on the surface becomes saturated soon and the reverse process occurs simultaneously with evaporation, so the molecules condense and return to the liquid state.
The difference between the number of molecules that leave the liquid and the number of molecules that return to it, marks the global nature of the phenomenon. If it is positive, evaporation occurs. If negative, condensation.

\section{Methodology}

According to the Conagua records through the National Meteorological Service prevailing in the state of Tabasco, it is possible to obtain information that allows establishing the mechanisms for analyzing the current situation regarding the behavior of temperature and relative humidity. The percentage of relative humidity will allow knowing the partial pressure of the air, in order to subsequently evaluate the molar composition of the air at the conditions prevailing in the state.

It is also necessary to know the molar composition of the liquid on the surface, that is to say at the liquid-gas interface, for this the vapor pressure of the water at the temperature at which said mass of liquid must be found is evaluated. With this information and knowing the total pressure that governs the state, which is at sea level, the molar composition at the interface is evaluated.

The proposed mathematical model that defines the behavior of the composition through a defined height, arises from applying a microscopic mass balance in a small differential element located in the liquid transfer zone, that is, in the region it occupies specifically air. This balance is carried out according to the principles of mass transfer, where it is known that there is no accumulation of matter in the system. It is necessary to know two specific conditions in said system, which will allow evaluating the integration constants that arise from the applied balance.

Finally, the mathematical equation obtained will allow to model the variation in the composition of the liquid from the area of the liquid-gas interface, up to a defined height that will be found precisely within the air.

When graphing the equation, it will be observed how said variation is affected by temperature, air speed, air humidity and the extended surface of said mass of liquid. 


\section{Analysis of previous data}

The results obtained from the relative humidity in the state of Tabasco during 25 days of the month of April of the year 2019, are concentrated in the following table:

\begin{tabular}{|l|r|r|}
\hline Day & \multicolumn{1}{c}{$\begin{array}{c}\text { Temperature } \\
{\left[{ }^{\circ} \mathrm{C}\right]}\end{array}$} & $\begin{array}{c}\text { Relative } \\
\text { Humidity } \\
(\mathrm{RH})[\%]\end{array}$ \\
\hline 01 & 21.9 & 86.9 \\
\hline 02 & 22.9 & 89.3 \\
\hline 03 & 25.8 & 76.5 \\
\hline 04 & 26.4 & 78.2 \\
\hline 05 & 28.8 & 62.4 \\
\hline 06 & 28.9 & 64.1 \\
\hline 07 & 28.8 & 66.6 \\
\hline 08 & 29.0 & 67.7 \\
\hline 09 & 25.9 & 77.8 \\
\hline 10 & 26.1 & 68.0 \\
\hline 11 & 27.7 & 59.0 \\
\hline 12 & 29.1 & 61.5 \\
\hline 13 & 31.1 & 50.3 \\
\hline 14 & 24.7 & 59.9 \\
\hline 15 & 25.4 & 69.7 \\
\hline 16 & 28.0 & 70.3 \\
\hline 17 & 28.2 & 73.7 \\
\hline 18 & 30.0 & 61.6 \\
\hline 19 & 26.7 & 66.5 \\
\hline 20 & 25.1 & 61.0 \\
\hline 21 & 26.3 & 53.5 \\
\hline 22 & 29.9 & 59.8 \\
\hline 23 & 28.0 & 67.2 \\
\hline 24 & 29.3 & 60.9 \\
\hline 25 & 29.9 & 60.5 \\
\hline
\end{tabular}

Table 1 Temperature and Relative Humidity of the municipality of Centro in the state of Tabasco from April 01 to 25,2019

Source: History of the climate in Villahermosa (https://www.meteored.mx/villahermosa/historico)

The secondary information source that was used allowed to evaluate the daily averages of temperature and relative humidity that were stored and processed in a database, to later be useful for the calculation and processing bases of all the information generated until the elaboration of the graphs of the final results.

\section{Results}

The data collected and concentrated in Table 1, allowed to evaluate the partial pressure of the water vapor in the prevailing region on the surface of the water, considering for these calculations only two temperature values $(20 \mathrm{oC}$ and $250 \mathrm{C}$ ), both the partial pressure values Since the molar fraction (yA) present very little variation, therefore, for the purposes of this calculation procedure.
An average of the total of the 25 values that were evaluated will be taken, it should be noted that the molar fraction reported in said Table was evaluated considering a total pressure of $101,325 \mathrm{kPa}$.

\begin{tabular}{|c|c|c|c|}
\hline \multicolumn{2}{|l|}{$\mathrm{T}=20^{\circ} \mathrm{C}$} & \multicolumn{2}{|l|}{$\mathrm{T}=25^{\circ} \mathrm{C}$} \\
\hline $\begin{array}{c}\text { Partial Pressure, } \\
\text { PA }_{\text {A }}[\mathbf{P a}]\end{array}$ & $\mathbf{y}_{\mathrm{A} 2}$ & $\begin{array}{c}\text { Partial Pressure, } \\
\mathbf{P A}_{\mathrm{A}}[\mathbf{k P a}]\end{array}$ & $\mathbf{y}_{\mathbf{A} 2}$ \\
\hline 2.0433 & 0.0202 & 2.7701 & 0.0273 \\
\hline 2.0997 & 0.0207 & 2.8466 & 0.0281 \\
\hline 1.7987 & 0.0178 & 2.4386 & 0.0241 \\
\hline 1.8387 & 0.0181 & 2.4928 & 0.0246 \\
\hline 1.4672 & 0.0145 & 1.9891 & 0.0196 \\
\hline 1.5072 & 0.0149 & 2.0433 & 0.0202 \\
\hline 1.5660 & 0.0155 & 2.1230 & 0.0210 \\
\hline 1.5918 & 0.0157 & 2.1581 & 0.0213 \\
\hline 1.8293 & 0.0181 & 2.4800 & 0.0245 \\
\hline 1.5989 & 0.0158 & 2.1676 & 0.0214 \\
\hline 1.3873 & 0.0137 & 1.8807 & 0.0186 \\
\hline 1.4460 & 0.0143 & 1.9604 & 0.0193 \\
\hline 1.1827 & 0.0117 & 1.6034 & 0.0158 \\
\hline 1.4084 & 0.0139 & 1.9094 & 0.0188 \\
\hline 1.6389 & 0.0162 & 2.2218 & 0.0219 \\
\hline 1.6530 & 0.0163 & 2.2410 & 0.0221 \\
\hline 1.7329 & 0.0171 & 2.3493 & 0.0232 \\
\hline 1.4484 & 0.0143 & 1.9636 & 0.0194 \\
\hline 1.5636 & 0.0154 & 2.1198 & 0.0209 \\
\hline 1.4343 & 0.0142 & 1.9445 & 0.0192 \\
\hline 1.2579 & 0.0124 & 1.7054 & 0.0168 \\
\hline 1.4061 & 0.0139 & 1.9062 & 0.0188 \\
\hline 1.5801 & 0.0156 & 2.1421 & 0.0211 \\
\hline 1.4319 & 0.0141 & 1.9413 & 0.0192 \\
\hline 1.4225 & 0.0140 & 1.9286 & 0.0190 \\
\hline
\end{tabular}

Table 2 Partial pressures evaluated from the temperature and relative humidity data in the municipality of Centro in the state of Tabasco from April 01 to 25, 2019 Source: Author's contribution (April 2019)

Calculating the average of the reported values we have:

\begin{tabular}{|c|c|c|c|}
\hline \multicolumn{2}{|c|}{$\mathrm{T}=20^{\circ} \mathrm{C}$} & \multicolumn{2}{|c|}{$\mathrm{T}=25^{\circ} \mathrm{C}$} \\
\hline Average Partial & & Average Partial & \\
\hline $\begin{array}{l}\text { Pressure, } \quad \mathrm{P}_{\mathrm{A}} \\
{[\mathrm{kPa}]}\end{array}$ & УA2(average) & $\begin{array}{l}\text { Pressure, } \quad \mathrm{P}_{\mathrm{A}} \\
{[\mathrm{kPa}]}\end{array}$ & УA2(average) \\
\hline 1.5734 & 0.0155 & 2.1331 & 0.0211 \\
\hline
\end{tabular}

Table 3 Partial pressure and average molar fraction for the calculation of the concentration profile

Source: Author's contribution (April 2019)

Vapor pressure is evaluated at the temperature at which the evaporating liquid is, in this case, for this study the average temperatures reported for rivers in the state are taken. Fluctuating the values between a range of 20 to $35^{\circ} \mathrm{C}$, for which four different temperatures were analyzed, presented below: 


\begin{tabular}{|l|r|r|}
\hline $\begin{array}{c}\text { Temperature } \\
{\left[{ }^{\circ} \mathbf{C}\right]}\end{array}$ & $\begin{array}{c}\text { Vapor } \\
\text { pressure }\left(\mathbf{P}_{\text {Av }}\right) \\
{[\mathrm{kPa}]}\end{array}$ & yA1 \\
\hline 20 & 2.3513 & 0.0232 \\
\hline 25 & 3.1877 & 0.0315 \\
\hline 30 & 4.2715 & 0.0422 \\
\hline 35 & 5.6609 & 0.0559 \\
\hline
\end{tabular}

Table 4 Vapor pressures evaluated at four different temperatures and corresponding mole fraction Source: Author's contribution (April 2019)

The matter balance applied to a differential element of finite thickness in the air zone is established without accumulation of matter, and the equations that govern this behavior are presented below:

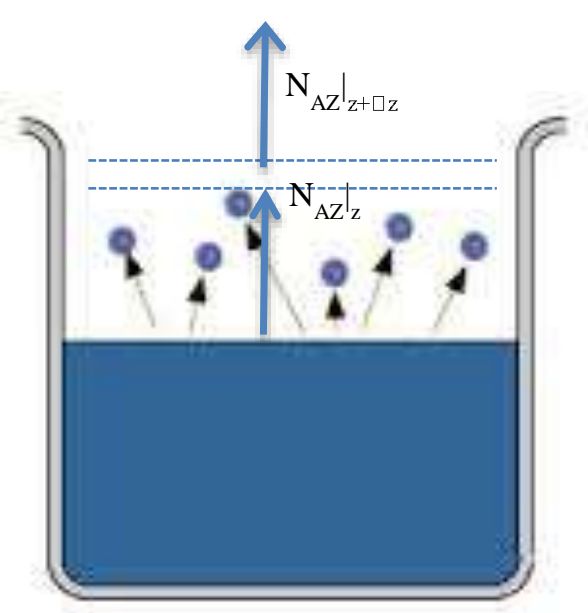

General balance of matter:

$\mathrm{E}-\mathrm{S}=0$

$\mathrm{N}_{\mathrm{A}}\left|\mathrm{Z}-\mathrm{N}_{\mathrm{A}}\right|_{\mathrm{z}+\Delta \mathrm{z}}=0$

This balance generates the following differential equation, (dividing equation 2 by $\Delta Z$ and applying limits):

$\frac{\mathrm{d} N_{A}}{d z}=0$

By introducing the corresponding general equation of molecular diffusion flow for the case that corresponds to this diffusion phenomenon, which is: Diffusion of " $\mathrm{A}$ " through "B" at rest, we have:

$N_{A}=-\frac{c D_{A B}}{\left(1-y_{A}\right)} \frac{d y_{A}}{d z}$

$\frac{\mathrm{d}}{d z}\left(-\frac{c D_{A B}}{\left(1-y_{A}\right)} \frac{d y_{A}}{d z}\right)=0$
This differential equation is solved by separation of variables, considering that both the total concentration and the diffusivity of the system ( $c$ and $\mathrm{D}_{\mathrm{AB}}$ ) are constant and it is possible to treat them mathematically to integrate this equation twice; and obtain the following equation as a result:

$-\operatorname{Ln}\left(1-y_{A}\right)=c_{1} z+c_{2}$

The constants of integration are evaluated by applying the prevailing system conditions in the environment, which are:

Para $\mathrm{z}=0 \quad \mathrm{y}_{\mathrm{A}}=\mathrm{y}_{\mathrm{A} 1}$

Para $\mathrm{z}=0.5 \mathrm{~m} \quad \mathrm{yA}_{\mathrm{A}}=\mathrm{y}_{\mathrm{A} 2}$

According to these it is possible to know the value of the constants and obtain the concentration profiles.

It is important to point out that once the integration constants are known, it is possible to obtain a general equation that outlines the behavior of the concentration of "A", through the height $\mathrm{z}$, and the concentration of $\mathrm{B}$ is obtained by difference, as shown in graph 1 .

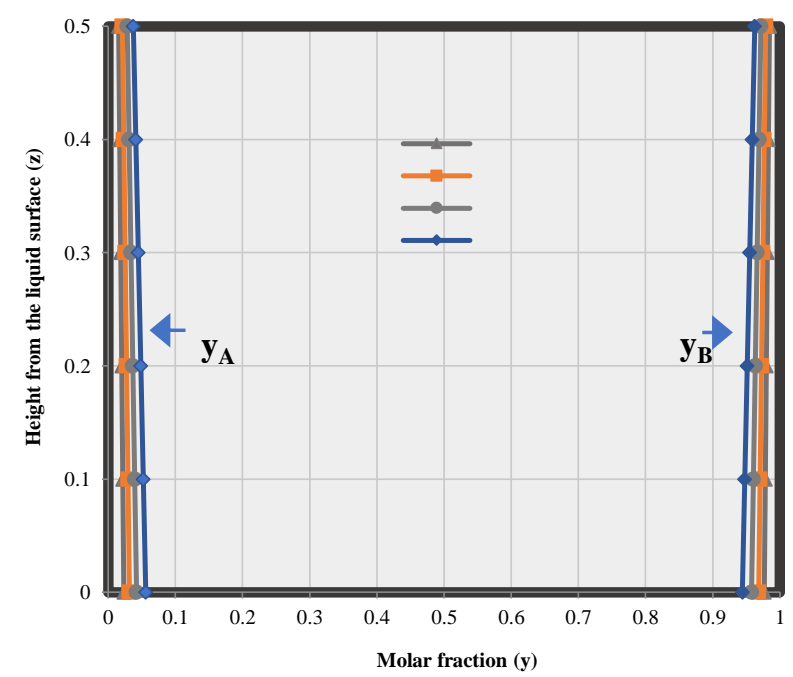

Graphic 1 Composition profile of water through air at different temperatures

Source: Author's contribution (April 2019)

The plotted concentration profiles were evaluated for four different temperatures of the evaporating liquid, the calculations are based on the relative humidity, the partial pressure and the integration constants of equation (6). 


\section{Conclusions}

The study of the behavior of the molecules during a vaporization process through a gas phase is of utmost importance in order to know the variation of the composition in transfer zones that allow an acceleration of the diffusion process. The amount of molecules that evaporate to a liquid phase is significantly dependent on relative humidity and temperature. The results of this study show that there is little variation in the composition of water through the air, observing an area of higher concentration just on the surface of the liquid. The model obtained from the balance presents a good prediction of the concentration profile. It should be noted that even when the relative humidity was $100 \%$, this profile does not present much variation, results that were obtained with great reliability in the application of the model.

\section{References}

Bird, R.B., Stewart, W.E., Lightfoot, E.N.,(1992). Fenómenos de Transporte. Ed. Reverté.

Hines, L., A., Maddox, N., R., (1987), Transferencia de Masa, Fundamentos y Aplicaciones. Prentice-Hall Hispanoamericana, S.A.

Manzur, A. y Cardoso J. (2015). Velocidad de Evaporación del agua. Revista Mexicana de Física. 61, 31-34.

Meteored. Histórico del clima en Villahermosa. https://www.meteored.mx/villahermosa/historic o

Reporte del Clima en México. (2019). Coordinación General del Servicio Meteorológico Nacional. CONAGUA. 